\title{
ACOMPANHAMENTO DAS ALTERAÇÕES POST-MORTEM (Glicólise) NO MÚSCULO DO JACARÉ DO PANTANAL (Caiman crocodilus yacare) ${ }^{1}$
}

\author{
Sebastião Roberto TABOGA², Pedro Fernando ROMANELLI ${ }^{3, *}$, Sérgio Luis FELISBINO4, \\ Luciano de Figueiredo BORGES ${ }^{4}$
}

\section{RESUMO}

Realizaram-se avaliações químicas, histológicas e medidas de $\mathrm{pH}$ ao longo do tempo da degradação do glicogênio no músculo longissumus dorsi do jacaré. A metabolização do glicogênio muscular durou em torno de 50 horas, situando-se o pH muscular inicial entre 6,6 e 6,7 e estabilizando-se, depois de 36 a 48 horas, em torno de 5,5-5,6. Oitenta a $85 \%$ do glicogênio inicial foi metabolizado nas primeiras 20 25 horas pós-abate. Histologicamente o teste do PAS revelou, ao longo do tempo de armazenamento refrigerado, um decréscimo dos grânulos de glicogênio.

Palavras-chave: glicólise; glicogênio muscular; pH muscular; jacaré do pantanal.

\section{SUMMARY}

POST-MORTEM ALTERATIONS (GLYCOLYSIS) OF PANTANAL ALLIGATOR'S (Caiman crocodilus yacare) MUSCLE. This paper presents a study of glycogen degradation in longissimus dorsi muscle of pantanal alligator. Glycogen concentration and muscle $\mathrm{pH}$ measurements were assessed. Glycolysis took about 50 hours to complete. Initial muscle pH value were in the limits of 6.6 and 6.7 and after 36 hours they dropped to 5.5-5.6. On the first $20-25$ hours postmortem $80-85 \%$ of inicial glycogen was metabolized. Through histologycal PAS test it was observed during cold storage a decrease on the number of glycogen granules. On the first $20-25$ hours postmortem $80-85 \%$ of inicial glycogen was metabolized.

Keywords: glycolysis; glycogen in muscle; muscle $\mathrm{pH}$; pantanal alligator.

\section{1 - INTRODUÇÃO}

O grande interesse pelo jacaré do Pantanal (Caiman crocodilus yacare) sempre, esteve relacionado, à exploração do couro. Ultimamente sua carne vem sendo comercializada em restaurantes especializados e com uma boa aceitação. Sobre isso, ROMANELLI [16], em estudos realizados com aplicação de análise sensorial, já havia destacado a aparência visual atraente e o sabor agradável, reforçando, por essas razões a viabilidade de utilização dessa carne, como mais uma opção de fonte protéica de origem animal, além de, ser uma atividade comercial complementar ao comércio de couro.

Com relação à qualidade de carne, a concentração de glicogênio do músculo no momento de abate tem uma grande influência nas reações bioquímicas post-mortem, as quais determinam a qualidade da carne para o consumo e processamento $[5,8]$.

A quantidade do glicogênio muscular está relacionado com o pH do músculo numa relação inversa com a quantidade do ácido láctico formado $[8,10]$. As características e propriedades da carne dependem da velocidade do declínio do $\mathrm{pH}$, bem como do seu valor final estabilizado. A degradação anormal do glicogênio muscular pode ocorrer devido ao estresse, como ficou muito bem demonstrado em suínos. Nestes o estresse pré-abate 1. Recebido para publicação em 03/07/2000. Aceito para publicação em 23/07/2000.

2. Departamento de Biologia - UNESP - Campus de São José do Rio Preto, SP, CEP 15054-000. E-mail: taboga@bio.ibilce.unesp.br

3. Departamento de Engenharia e Tecnologia de Alimentos - UNESP Campus de São José do Rio Preto, SP, CEP 15054-000. E-mail: romaneli@eta.ibilce.unesp.br

4. Departamento de Biologia - UNESP-Campus de São José do Rio Preto, SP, CEP 15054-000.

* A quem a correspondência deve ser enviada. causa diminuição brusca do $\mathrm{pH}$, antes da dissipação de calor da massa muscular do animal, e, como conseqüência, ocorre a desnaturação das proteínas musculares, afetando propriedades bioquímicas e tecnológicas tais como: diminuição da capacidade de retenção de água, mudanças na aparência da cor normal da carne, um fenômeno chamado de PSE ( pale, soft, exudative) [10].

Por outro lado, animais abatidos em condições de estresse por um período mais prolongado apresentam pouca variação do $\mathrm{pH}$ da massa muscular em relação aos animais abatidos em condições normais, causada pela baixa concentração do glicogênio no momento de abate. Nesse caso, o pH final fica estabilizado em um valor maior e, como conseqüência, as proteínas musculares tem uma maior capacidade de retenção de água (CRA). A carne é pegajosa e escura, além de ser mais susceptivel à contaminação microbiológica, um fenômeno chamado de DFD (dark, firm, dry) [6, 20].

Devido à importância da qualidade da carne foi nosso propósito acompanhar as alterações metabólicas pósabate no músculo do jacaré, através de medidas da concentração de glicogênio do músculo, do declínio do $\mathrm{pH}$ e observações histológicas ao longo do tempo de metabolização.

\section{2 - MATERIAL E MÉTODO}

\section{1 - Abate}

Utilizaram-se 05 jacarés machos, filhos de pais selvagens, da espécie Caiman crocodilus yacare, criados em cativeiro com autorização do IBAMA. Pesavam entre 16 a $20 \mathrm{Kg}$ e foram abatidos com tiros de revólver, na cabeça, entre os olhos, método que, provoca morte instantânea, e evita, além da mutilação o stresse pré-abate [18]. 


\section{2 - Preparo de Amostras e Análises}

Após o abate do animal, procedeu-se a sangria, esfola e lavagem abundante com água. A partir daí preparou-se a carcaça, constituída de tronco, cauda e membros.

Do corte da cauda separaram-se amostras, de $\pm 1,0$ grama, para medidas da concentração de glicogênio, as quais foram retiradas em duplicatas do músculo longissimus dorsi, entre 30 a 60 minutos pós-abate (considerado aqui como "tempo zero"). Após a retirada das amostras, o corte da cauda foi prontamente armazenado para as medidas seguintes, em câmaras frias de ar circulante com temperaturas oscilantes entre $3-6^{\circ} \mathrm{C}$.

As análises foram realizadas em intervalos de tempo que variaram de 2 a 5 horas, até atingir a completa estabilidade do $\mathrm{pH}$. As dosagens de glicogênio foram determinadas utilizando-se o reagente de antrona e medidas espetrofométricas a $620 \mathrm{~nm}$ de acordo com a literatura [9].

As determinações do $\mathrm{pH}$ do músculo foram realizadas imediatamente após o abate, até a estabilidade do $\mathrm{pH}$ no pós rigor, quando praticamente todas as mudanças metabólicas já tinham sido completadas, com duração de aproximadamente 30-40 horas. Para esse estudo, amostras do músculo longissimus dorsi, em duplicata, com 4-5g de músculo, foram trituradas e homogeneizadas com $30 \mathrm{~mL}$ de solução de iodoacetato $0,005 \mathrm{M}$, seguindose leitura no pHmetro de acordo com os procedimentos indicados $[4,8]$.

As amostras para o estudo histológico foram coletadas nos mesmos intervalos de tempo utilizados para a determinação do glicogênio. Para isso, fragmentos de aproximadamente $5 \mathrm{~mm}^{3}$ do músculo longissimus dorsi foram coletados e mantidos em temperaturas entre $3-6^{\circ} \mathrm{C}$.

Após a coleta, as amostras foram fixadas em solução de Bouin por 24 horas, seguindo-se lavagem com álcool a $70 \%$ por mais 24 horas, e foram processadas pela técnica de inclusão em parafina [3]. Do material incluído na parafina foram feitos cortes histológicos de $5 \mu \mathrm{m}$ de espessura em micrótomo rotativo manual Reishert, os quais, depois de distendidos em lâminas com auxílio de banho-maria histológico, foram desparafinizados em xilol P. A, hidratados e submetidos ao teste do P. A.S para polissacarídeos.

O tratamento com $\alpha$-amilase salivar precedeu o teste do P. A.S, e foi realizado para a confirmação de que os pontos observados nos cortes do segmento muscular seriam grânulos de glicogênio. Para esse teste as lâminas, depois de hidratadas, foram incubadas com a enzima $\alpha$-amilase salivar, numa concentração de (1:1) em água destilada durante 30 minutos a $37^{\circ} \mathrm{C}$. Posteriormente lavaram-se os cortes em água destilada.

Para o teste do P. A.S. (Periodic Acid \& Schiff) segundo Lillie [14], depois de hidratados, os cortes foram oxidados em ácido periódico a $5 \%$ por cerca de 1 hora, seguindo-se lavagem com água destilada. Após esta etapa, os cortes foram submetidos ao reativo de Schiff, lavados em metabilssulfito de sódio 3 vezes durante 15 minutos cada, lavados novamente em água, desidratados em série alcoólica, diafanizados em xilol P. A e montados em Bálsamo de Canadá.

As lâminas histológicas foram analisadas e fotomicrografadas em fotomicroscópio Zeiss-Jena, modelo Jenaval, acoplado a sistema automático de fotografia. Os filmes utilizados para a documentação foram Kodak -T-max, asa 100.

\section{3 - RESULTADOS E DISCUSSÃO}

É sabido que a velocidade do declínio de $\mathrm{pH}$ e o seu valor final refletem as características da glicólise, as quais são de importância fundamental na qualidade da carne.

No músculo longissumus dorsi do jacaré observou-se a variação do glicogênio e do $\mathrm{pH}$ a partir do tempo zero até que a concentração do glicogênio tendesse a zero, e o $\mathrm{pH}$ permanecesse estabilizado (Figura 1). Uma diminuição acentuada do glicogênio ocorreu nas primeiras 2025 horas quando $80-85 \%$ da concentração inicial foi metabolizada; seguiu-se um período com queda menos acentuada, até uma quase estagnação da concentração após aproximadamente 40 horas.

Durante a glicólise, após uma diminuição nas primeiras 15-20 horas, o pH muscular inicial de 6,7-6,6 atingiu o valor aproximado de 6,0; continuou declinando, e após 36-48 horas, atingiu um $\mathrm{pH}$ final entre 5,5-5,7. Os resultados de estudo com baleia [12] foram diferentes dos de nosso trabalho. Observaram que a fase estacionária do $\mathrm{pH}$ ocorre no início do abate e dura cerca de 18 horas. Seguindo-se de uma queda brusca do $\mathrm{pH}$, a uma temperatura de $35^{\circ} \mathrm{C}$.

A literatura [2] faz observações sobre as variações do $\mathrm{pH}$ durante o rigor mortis também em peixes. Destaca que nestes é de curta duração, quando comparado com o dos mamíferos, e que, de uma maneira geral, oscila de 1 a 7 horas post mortem, o pH inicial variando de 7,0-7.3 e final de 6,2-6,5. Tais dados os diferenciam, também do jacaré do pantanal.

No entanto, no estudo com peixes observa-se que existem algumas espécies com $\mathrm{pH}$ final variando de 5,5 a 5,9. Parece que a busca por novidades que levem a novos conhecimentos sobre a glicólise e suas conseqüências tem estimulado pesquisas com espécies não convencionais de consumo humano. Assim, em estudos recentes com tilápias (Orochromis spp. ) criadas em cativeiro, avaliou-se as características do rigor mortis (RM) em músculos armazenados sob temperaturas de $0^{\circ} \mathrm{C}, 10^{\circ} \mathrm{C}$ e $27^{\circ} \mathrm{C}$. Observou-se que a $0^{\circ} \mathrm{C}$ ( 24 horas ) o avanço do RM ocorreu precocemente (muito cedo), quando comparado com músculos armazenados a $10^{\circ} \mathrm{C}(48$ horas), sendo que, a $27^{\circ} \mathrm{C}$ o RM total não foi atingido . Nesse trabalho estudou-se também a estabilidade dos músculos nas 3 temperaturas, verificando-se que a $0^{\circ} \mathrm{C}$ a vida-de-prateleira foi de 21 dias, de 9 dias a $10^{\circ} \mathrm{C}$ de , mas os autores não citaram os resultados da estabilidade dos músculos sob temperatura de $27^{\circ} \mathrm{C}$.

$\mathrm{O}$ acompanhamento da vida de prateleira foi realiza- 
do com medidas sensoriais e determinações do nitrogênio volátil total (NVT) [ 21].

Em outro trabalho recente realizado em diferentes músculos de avestruz obteve-se $\mathrm{pH}$ inicial variando de 7,13-6,31 e, depois de 24 horas, um pH final estabilizado entre 5,92-6,13 [17].

Os primeiros estudos do rigor mortis em músculo bovino [13] fizeram observações sobre a influência da temperatura na queda do $\mathrm{pH}$. Concluiram que o $\mathrm{pH}$ muscular abaixou de 7 para 6 em menos de 4 horas, em temperatura de $37^{\circ} \mathrm{C}$, mas demorou cerca de 20 horas sob temperatura de $7^{\circ} \mathrm{C}$, resultados estes, semelhantes aos obtidos no trabalho com o jacaré.

Em estudo sobre acompanhamento da glicólise, através de medidas de metabólitos [10] com os músculos do pescoço de bovinos, foi observada uma queda no $\mathrm{pH}$ muscular de 6,6 para menos de 6 após 15 horas de abate, a uma temperatura de $20^{\circ} \mathrm{C}$, com uma fase estacionária próxima do $\mathrm{pH}$ final de 5,6 . Verificou-se também uma alta concentração de glicogênio $\cong 70$ unidades de glicogênio medido em unidades de glicose/g amostra) no momento do abate, e uma baixa concentração ( menos de 10 unidades de glicogênio) após 15-20 horas pós-abate associado a um baixo valor de $\mathrm{pH}(\cong 5,7)$.

Em trabalho mais recente com bovinos [19], estudou-se a influência do pH final após a glicólise na maciez durante a maturação. Trabalhou-se com os músculos longissimus thoracis e lumborum de 3 grupos de animais: grupo $\mathrm{n}, \mathrm{pH}$ normal, entre 5,5 a 5,8 , grupo $\mathrm{m}$, tipo DFD moderado, pH entre 5,8 a 6,2 , e grupo c tipo DFD consumado, pH entre 6,2 a 6,7, e a maciez medida em amostras cozidas no Warner-Bratzler shear force (WBSF) em unidades $\mathrm{Kg} / \mathrm{cm}^{2}$.

Os resultados mostraram que a maciez aumentou com o tempo de maturação dentro do mesmo grupo e que em média, dos três grupos foi de $\cong 12,5 \mathrm{Kg} / \mathrm{cm}^{2}$ para o $1^{\circ}$ dia, $\cong 9 \mathrm{Kg} / \mathrm{cm}^{2}$ para o $6^{\circ}$ dia ,e $\cong 8,5 \mathrm{Kg} / \mathrm{cm}^{2}$ para o $13^{\circ}$ dia . Também foi possivel observar que dentre os 3 grupos, o grupo c foi o que apresentou os melhores resultados de força de cisalhamento $(\mathrm{FC}) \mathrm{com} \cong 9,5,6$ e $6 \mathrm{Kg} / \mathrm{cm}^{2}$ nos dias 1, 6 e 13 de maturação respectivamente, seguido do grupo $\mathrm{m}$ com $\cong 12,8,9,2$, e $8,2 \mathrm{Kg} / \mathrm{cm}^{2}$ no período considerado, ficando o grupo $\mathrm{n}$ com os piores resultados ( maiores valores) $\left(15,2,11,6\right.$, e $12,3 \mathrm{Kg} / \mathrm{cm}^{2}$ respectivamente nos dias 1, 6 e 13 ). Outra observação é que o pH aumentou linearmente em direção oposta ao grupo de menor força de cisalhamento ou seja, grupo n (média $\cong 13 \mathrm{Kg} /$ $\mathrm{cm}^{2}$ e $\mathrm{pH} 5,7$ ), grupo $\mathrm{m}$ ( média de $\cong 10 \mathrm{Kg} / \mathrm{cm}^{2}$ e pH 6,1), e grupo c ( média de $\cong 7,1$ e pH 6,5).

Pela sua importância, a literatura cita vários trabalhos recentes envolvidos com o tema. O estudo da eletroforese em gel de policrilamida (Page-SDS),com músculos do peito de perú que sofreram glicólise rápida ( $\mathrm{pH} \leq 5,8,15 \mathrm{~min}$ pós-abate (PA), características de carne tipo PSE), revelou bandas de fragmentos da degradação de miosina correspondentes a 133, 142, e $165 \mathrm{Kda}$ decorrentes da desnaturação das proteínas miofibrilares, bandas estas, não presentes em amostras tomadas como padrão ( queda do $\mathrm{pH}$ da glicólise considerada normal, $\mathrm{pH}>6,0,15$ minutos $\mathrm{PA}$ ) [15].

Baseado em trabalho verificado em frangos, onde o atordoamento por corrente elétrica parece inibir reações bioquímicas pós-abate (PA) acarretando atraso do rigor mortis, foi realizado um trabalho também com músculos do peito de perú onde estudou-se, o efeito da insensibilização ( atordoamento) no desenvolvimento do rigor mortis .

Os resultados mostraram que houve um atraso de 2 (duas) horas no desenvolvimento do rigor mortis com o grupo de aves atordoadas, quando comparado com o grupo controle (não atordoado). Neste estudo, os seguintes parâmetros foram avaliados: acompanhamento da queda do $\mathrm{pH}$, valor $\mathrm{R}$ (medida rápida para avaliar o estabelecimento do rigor mortis), valor $\mathrm{L}^{*}$ (eixo da intensidade luminosa, do sistema CIE-LAB), comprimento do sarcômero e valor da força de cisalhamento (FC) [1].

Outro estudo sobre atordoamento, mas com músculos do peito de frango (Pectoralis major), foi verificado o efeito de diferentes intensidades elétricas da insensibilização (300 pulsos de baixa voltagem, ou seja, variação da freqüência de pulsos entre $1 / \mathrm{s}$ a $10 / \mathrm{s}$ e os pulsos entre 5 a 20ms) e suas conseqüências na glicólise e na qualidade da carne (com medidas de $\mathrm{pH}$, comprimento do sarcômero e maciez após cozimento caseiro). A variação da intensidade elétrica foi avaliada pela velocidade do bater asas pós-abate. As medidas de $\mathrm{pH}$ foram realizadas pelo método de iodoacetato, como no presente trabalho com o jacaré. Os resultados obtidos mostraram que a variação da intensidade elétrica no atordamento não teve nenhum efeito na glicólise e na qualidade da carne estocada sob refrigeração [7].

A influência da variação da temperatura (tempo/temperatura) e a queda do $\mathrm{pH}$ sobre a glicólise, também foram estudadas em animal selvagem. No bisão, acompanhou-se a influência da temperatura de $10^{\circ} \mathrm{C}$ durante $10 \mathrm{~h}$, com relação à temperatura (variação entre $0^{\circ} \mathrm{C}$ a $2^{\circ} \mathrm{C}$ ) durante 24 horas, em 2 músculos (M. longissimus lumborum e M. semimembranosus) para avaliar a qualidade da carne com relação aos efeitos causados pelo frio.

Os resultados desse estudo mostraram que a glicólise na carcaça exposta a condições relativamente elevadas de temperatura, foi acelerada e acompanhada do correspondente declínio de $\mathrm{pH}$, de uma pigmentação (cor) bastante intensa e de uma significativa melhora na maciez, no início e durante a maturação. [11].

Em nossos estudos com o jacaré, os resultados mostrados na Figura 2. são referentes a vários ensaios, ao longo do tempo, em diversos animais. Como os resultados obtidos em todos os ensaios são semelhantes, foram escolhidas as melhores fotomicrografias de cada etapa para representar a seqüência da degradação metabólica do glicogênio.

Também como resultado de vários ensaios, aparece, pelo mesmo motivo seletivo, uma mistura de cortes musculares transversais e longitudinais, os quais são os que mais destacam a marcação citológica do glicogênio. 
A Figura 2 evidencia a diminuição do número de grânulos de glicogênio ao longo do tempo. Pela análise das lâminas histológicas, também pode-se observar uma discreta redução no volume celular, o que faz com que as fibras se afastem, como pode ser observado na Figura $2 i$.

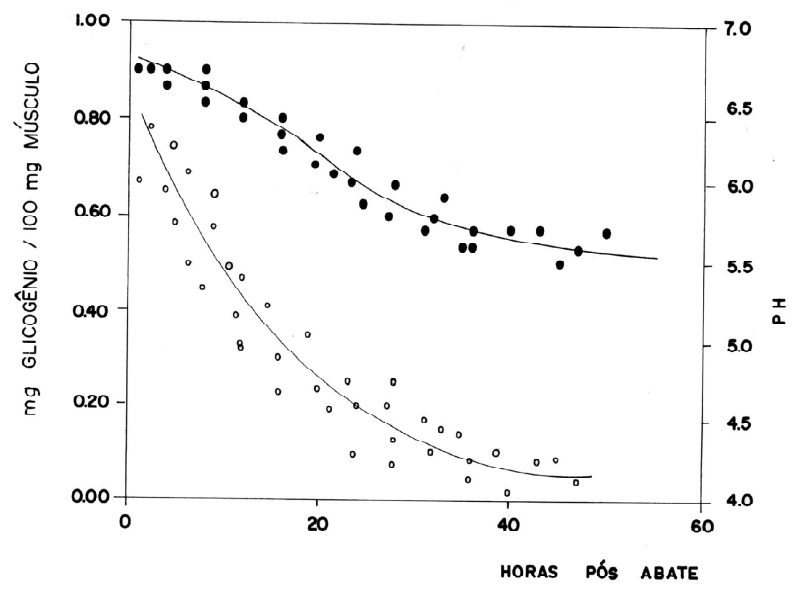

- $P_{11}$

Glicogênio

FIGURA 1. Acompanhamento da glicogenólise ao longo do tempo no músculo Longissimus dorsi do jacaré do Pantanal $\left(3-6^{\circ} \mathrm{C}\right)$
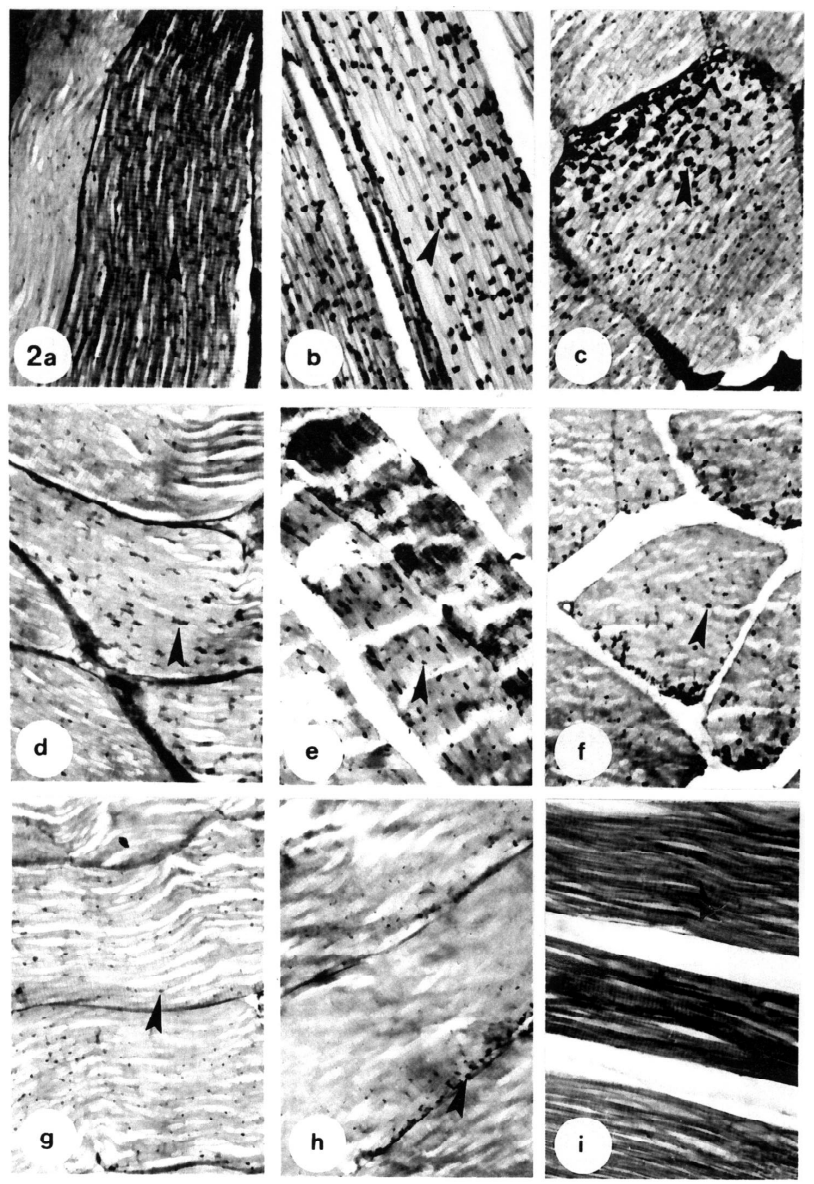

FIGUIRA 2. Acompanhamento citoquímico da glicogenólise no músculo Longissimus dorsi do jacaré $\left(3-6^{\circ} \mathrm{C}\right)$. (a) zero hora (b) quatro horas (c) oito horas (d) 12 horas (e) 18 horas (f) 24 horas (g) 35 horas (h) 45 horas (i) 48 horas. Na fig. (c) fica bem visivel que os grânulos de glicogênio se concentram mais na periferia celular. Observa-se claramente a diminuição do numero de grânulos de glicogênio com o passar do tempo. ( Cortes transversais longitudinais com aumento de $400 \mathrm{X}$ )

Possivelmente esta redução de volume seja devido ao armazenamento, em refrigeração, em que naturalmente ocorre perda de umidade, reduzindo o volume celular. Nesse estudo histológico também foi possivel verificar que os grânulos de glicogênio do músculo longissimus dorsi estão concentrados mais próximos à periferia das células onde se situa o endomísio, e estão voltados para a região dos vasos sangüíneos. Sabe-se que é na periferia celular que o acúmulo e a retirada desses grânulos se dão de uma maneira mais rápida*. Verificou-se que a concentração dos grânulos nas células foi variável.

A Figura 3 mostra o tratamento dos cortes histológicos, realizado com $\alpha$-amilase salivar. Esse tratamento serviu para confirmar se os grânulos eram mesmo de glicogênio, pois, a ação da enzima ocasionou o desaparecimento das marcações citológicas, as quais poderiam, se ainda presentes, ser de glicoproteínas e/ou glicosaminoglicanos ácidos. Estes também reagem com o P. A.S mas não sofrem a ação da enzima permanecendo ainda no endomísio (Figuras 3b, 3d).

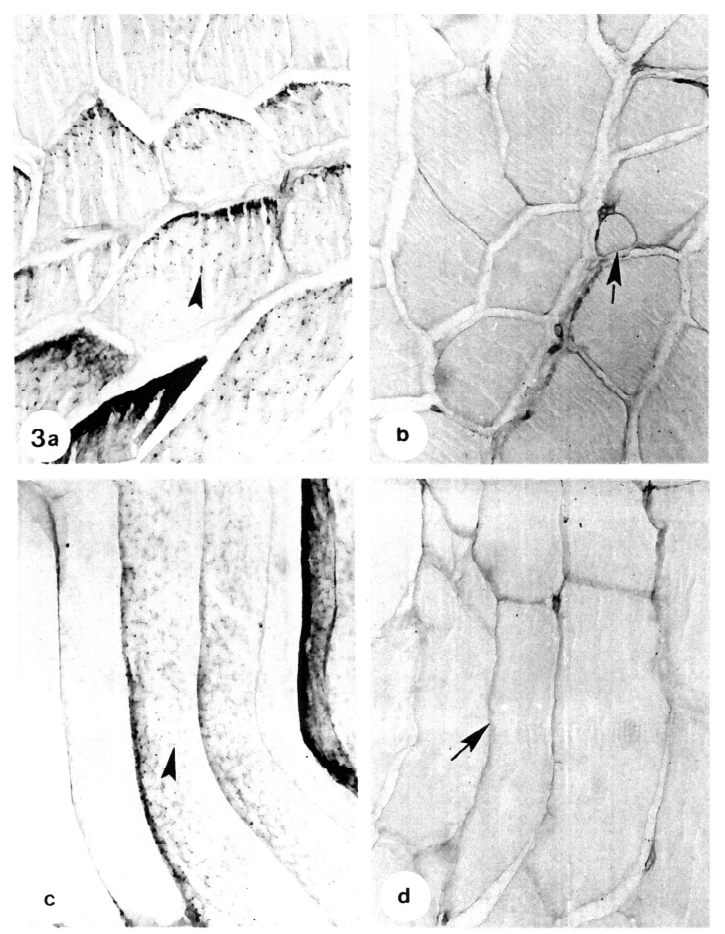

FIGURA 3. Confirmação histoquímica da presença do glicogênio de cortes histológicos transversais ( $a-b)$ e longitudinais (cd). Presença de grânulos de glicogênio (a-c). Ausência dos grânulos de glicogênio (b-d), removidos após a ação da $\alpha$-amilase. (Aumento $250 \mathrm{X}$ ).

* GREEP,D.O. \& WEISS, L. Histogia . Editora Atheneu, Buenos Aires, 1978. $891 p$. 


\section{4 - CONCLUSÕES}

- A glicólise do músculo longissimus dorsi do jacaré demorou em torno de 36-48 horas, passando de um $\mathrm{pH}$ inicial entre 6,6-6,7 para um $\mathrm{pH}$ praticamente estabilizado de 5,5-5,7, em uma temperatura de $3-6^{\circ} \mathrm{C}$.

- Visualizou-se a glicogenólise ao longo do tempo, através do desaparecimento dos grânulos de glicogênio, com marcações citoquímicas, mas a variação foi elevada.

\section{5 - REFERÊNCIAS}

[1] ALVARADO, C. Z. \& SAMS, A. R. Rigor mortis development in turkey breast muscle and the effect of electrical stunning. Poultry Science, v. 79, n. 11, p 1694-1698, 2000.

[2] AMILACHER, A. Rigor mortis in fish. In: BORGSTROM,G. ed. Fisch as food. New York, Academic Press, 1965. v.1, p. 385-409.

[3] BEHMER, O. A.;TOLOSA, E.M.C.; FREITAS NETO,A.G. Manual de técnicas para histologia normal e patológica. São Paulo, Edart, USP, 1976. p. 31-52.

[4] DUTSON,T.R. The measure of $\mathrm{pH}$ in muscle and its importance to meat quality. In: Reciprocal meat conference, 36.,1983. Procedings. p. 92-97.

[5] FABIANSSON, S. \& REUTERSWARD, A.L. Glycogen determinations in post-mortem beef muscle. Food Chem., n. 15, p. 269-284, 1984.

[6] FORREST, J.C.;ABERLE, E.D.; HEDRICK,H.B.; JEDGE, M.D.;MERKEL, R.A. Fundamentos de ciências de la carne. Zaragoza, Acribia, 1979, 364p.

[7] GAULT, N.F.S. et al. Effect of some eletrical stimulation variables on wing flapping, post-mortem glycolysis and eating quality characteristics of broiler Pectoralis major muscle. British Poutry Science, v. 41, n. 3, p. 293299, 2000.

[8] GIRE, P. \& MONIN, G. Taux de glycogene musculaire, stress de transport et $\mathrm{pH}$ ultime de la viande chez le mouton. Ann.Technol. Agric., v. 28, n. 4, p. 433-444, 1979.

[9] HANDEL,E.van. Estimation of glycogen in small anounts of tissue. Analyt. Biochem., n. 11, p. 2256-2265, 1965.
[10] HONIKEL, K.O. ; FISCHER, C. ; HAMM, R. Characteristics and utilization of pre rigor meat. Ann. Technol. Agric., v. 29, n. 4, p. 589-602, 1980.

[11] JAM, J. et al. The influence of elevated temperature conditioning on bison (Bison bison bison) meat quality. Meat science, v. 56, n. 3, p. 279-284, 2000.

[12] MARSCH, B.B. Obsevations on rigor mortis in whale muscle. Biochim. Biophys. Acta, n. 9, p. 127-132, 1952.

[13] MARSCH, B.B. Rigor mortis in beef. J.Sc.Food Agric., v. 5, n. 2, p. 70-75, 1954.

[14] MELLO, M.L.S. \& VIDAL, B.C. Práticas em Biologia Celular. Edgard Blücher Funcamp, Campinas, SP. 1980.

[15] RATHGEBER, B.M. et al. Rapid post-mortem glycolisis and delay chilling of turkey carcasses cause alterations to protein extractability and degration of breast muscle proteins. J. Agric. Food Chem., v. 47, n. 7, p. 25292536, 1999.

[16] ROMANELLI, P. F. Propriedades Tecnológicas da carne de jacaré do Pantanal (Caiman crocodilus yacare). Campinas, 1995.Tese de Doutorado. Faculdade de Engenharia de Alimentos. Universidade Estadual de Campinas.

[17] SALES, J. \& MELlET, F. D. Post-Mortem pH Decline in Different Ostrich Muscle. Meat Science, n. 42, p. 235238, 1996.

[18] SECRETARIA DA AGRICULTURA DO ESTADO DE SÃO PAULO, Departamentode Zoologia. Manual de coleta e preparação de animais terrestres e de água doce. São Paulo, 1967, p. 84-98.

[19] SILVA, J. A.; PATARATA, L. ; MARTINS, C. Influence of ultimate $\mathrm{pH}$ on bovine meat tenderness during ageing. Meat Science, n. 52, p. 453-459, 1999.

[20] TARRANT, P. V. Muscle biology and biochemistry. In: EUROPEAN MEETING OF MEAT RESEARCH WORKERS, 1987. Proceedings..., v. 1, p. 1-5.

[21] TOME,E et al . Effects of storage temperature on the onset of rigor mortis and stability of cultured tilapia (Oreochromis spp) .Revista Cientifica - Facultad de Ciências Veterinarias, v. 10, n. 4, p. 339-345, 2000.

\section{6 - AGRADECIMENTOS}

Os autores agradecem ao IBAMA pela colaboração prestada. 